\title{
Seismic Forces in Ancillary Components Supported on Piers and Wharves
}

\author{
Rakesh K. Goel, ${ }^{\text {a) }}$ M.EERI
}

\begin{abstract}
This paper presents a simple procedure to estimate seismic forces in ancillary components (secondary systems) supported on marine structures such as piers, wharves, and marine oil terminals (primary systems). Since many such marine structures can be idealized as single-degree-of-freedom (SDOF) systems, this study uses a simple linear-elastic model with two DOF, one representing the marine structure and the other representing the ancillary component. This study shows that acceleration at the base of the secondary system is approximately equal to spectral acceleration at the fundamental period of the primary system. It also proposes a formula, which is an improvement over current ASCE 7-10 recommendations, to estimate acceleration amplification in the secondary system due to its flexibility when mass and period ratios of the secondary and primary systems are known. The procedure in this paper is strictly applicable to marine structures for which primarily a single mode contributes to seismic response. [DOI: 10.1193/041017EQS068M]
\end{abstract}

\section{INTRODUCTION}

Marine structures such as piers and wharves at port facilities and marine oil terminals (primary systems) often support ancillary components such as fire protection, fire detection, emergency shutdown, electrical power systems, piping and pipelines, mechanical and electrical equipment, marine loading arms, and other nonbuilding structures such as control rooms, storage sheds, and oil transfer towers (secondary systems) that are not part of the lateral load-resisting system of the main structure. Several codes or standards, such as ASCE/COPRI 61-14 (ASCE 2014), MOTEMS (CSLC 2016), and UFC 4-152-01 (DoD 2017), offer seismic design procedures for primary systems in marine structures. Additionally, various ports, such as Long Beach (POLB 2012), Los Angeles (POLA 2010), and San Francisco (POSF 2012), also offer seismic design procedure for primary structures as part of their own seismic design criteria. For seismic design of secondary systems, however, these documents often refer to other documents such as ASCE 7-10 (ASCE 2010), FEMA-356 (ASCE 2000) and FEMA-450 (BSSC 2003), CalARP or ASCE Guidelines (CalARP 2013, ASCE 2011), CCR Title 2 (OAL 2017), CFR Title 33 (GPO 2017), and OCIMF Specifications (OCIMF 1999). For example, MOTEMS (CSLC 2016) references several other documents (Table 1) and UFC 4-152-01 (DoD 2017) and ASCE/COPRI 61-14 refer to ASCE 7-10. Port documents-for example, POLB (2012), POLA (2010), and POSF (2012) - appear to be silent about seismic design of ancillary components.

\footnotetext{
a) Associate Dean and Professor of Civil and Environmental Engineering, College of Engineering, California Polytechnic State University, San Luis Obispo, CA 93407.
} 


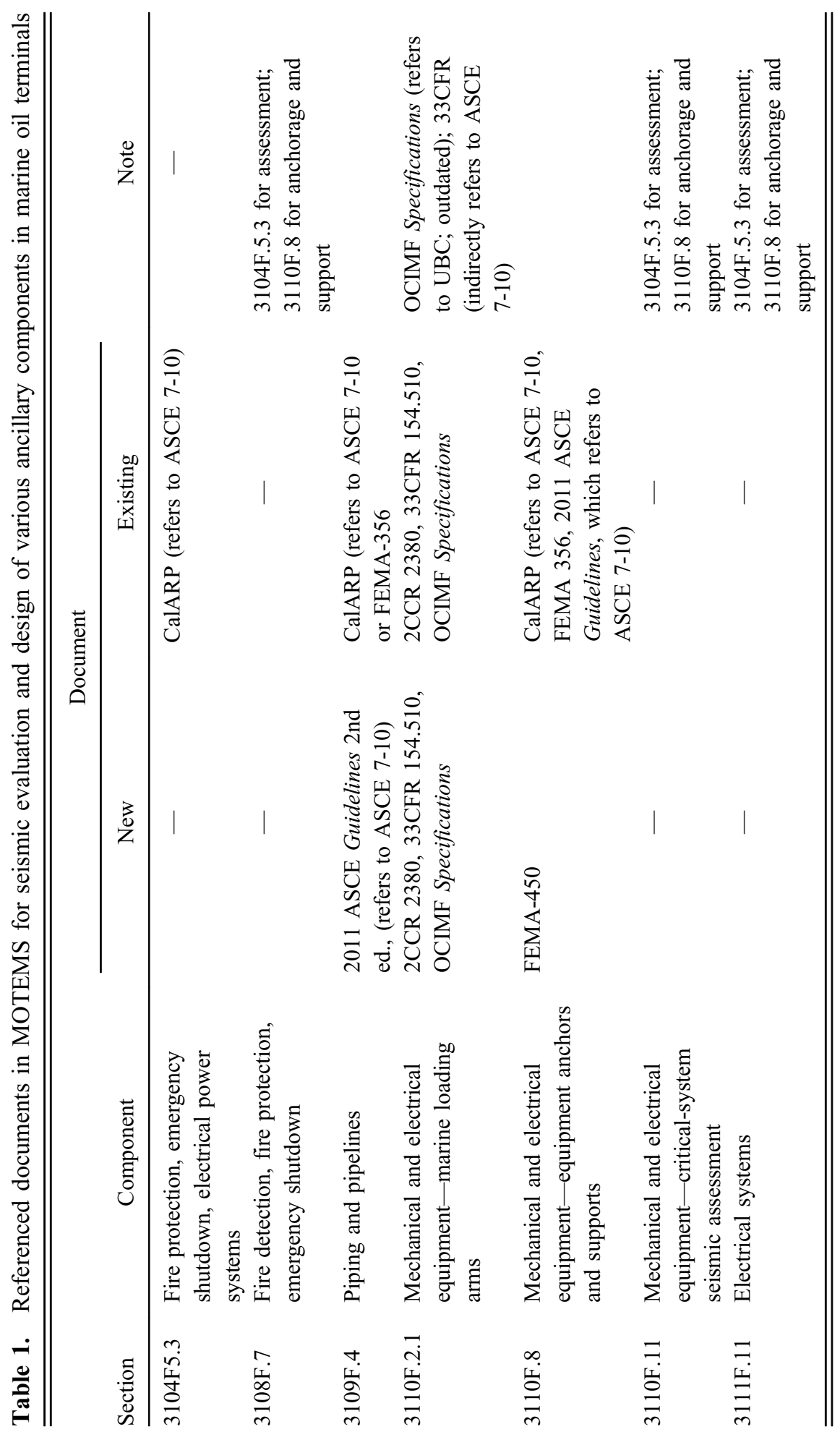


A further examination of documents for seismic design of marine structures indicates that they generally refer to the ASCE 7-10 procedure for seismic design of nonstructural components, which in turn draws from FEMA-356 and FEMA-450. It is useful to note that ASCE 7-10, FEMA-356, and FEMA-450 are primarily for secondary systems in buildings. Marine structures such as piers, wharves, and marine oil terminals differ significantly in configuration and seismic behavior from building structures. Therefore, there is a need to develop a procedure to estimate seismic forces in ancillary components and nonbuilding structures which captures special features and behavior of piers, wharves, and marine oil terminals during seismic loading.

\section{ASCE 7-10 SEISMIC PROVISIONS}

ASCE 7-10 (ASCE 2010) computes horizontal seismic forces in nonstructural components or nonbuilding structures supported on other structures with weight less than $25 \%$ of the combined effective weights of the two as follows:

$$
\begin{aligned}
& F_{p}=\frac{0.4 a_{p} S_{D S} I_{p} W_{p}}{R_{p}} 1+2 \frac{z}{h} \\
& 0.3 S_{D S} I_{p} W_{p} \leq F_{p} \leq 1.6 S_{D S} I_{p} W_{p}
\end{aligned}
$$

where $S_{D S}=$ short period spectral acceleration, $a_{p}=$ component amplification factor, $I_{p}=$ component importance factor, $R_{p}=$ component response modification factor, $W_{p}=$ component operating weight, $z=$ height in structure of point of attachment of component with respect to the base, and $h=$ average roof height of the structure with respect to the base. Several Tables in ASCE 7-10 present the values of $a_{p}$ and $R_{p}$ for different types of nonstructural components. The coefficient $a_{p}$ is typically set equal to 1 for rigid components and 2.5 for flexible components. ASCE 7-10 permits a lower value of $a_{p}$ for flexible components if justified by detailed dynamic analysis. The provisions in FEMA-356 and FEMA-450 are generally similar to those in ASCE 7-10. However, the types of nonstructural components and, in some cases, the values of $a_{p}$ and $R_{p}$ may differ.

The term $0.4 S_{D S}$ in Equation 1 represents acceleration at the ground level, and $(1+2 z / h)$ accounts for acceleration amplification from the ground to the point of attachment (or base) of the nonstructural component in the building. The term $a_{p}$ represents further acceleration amplification in the component itself.

Both FEMA-450 and ASCE 7-10 also permit an alternative method to compute $F_{p}$ when acceleration at the point of attachment is available from the modal (or response spectrum) method:

$$
F_{p}=\frac{a_{i} a_{p} I_{p} A_{x} W_{p}}{R_{p}}
$$

in which $a_{i}=$ acceleration at the point of attachment of the component, and $A_{x}=$ torsional amplification factor given by

$$
A_{x}={\frac{\delta_{\max }}{1.2 \delta_{\mathrm{avg}}}}^{2} \quad 1 \leq A_{x} \leq 3
$$


where $\delta_{\max }$ is the maximum displacement, and $\delta_{\text {avg }}$ is the average of the displacements at the extreme points of the structure (see Figure 1). The upper- and lower-bound limits of Equation 1 apply to force computed from Equation 2 as well.

Equation 2 essentially replaces $0.4 S_{D S}(1+2 z / h)$ with $a_{i}$ and considers further amplification because of torsion. Finally, if the fundamental period of the structure, $T_{n}$, and the period of the flexible nonstructural component, $T_{p}$, are known, ASCE 7-10 provides guidelines for estimating $a_{p}$ as shown in Figure 2.

\section{NEED FOR REVISED PROVISIONS}

It is clear from the presentation so far that seismic force in a secondary system supported by a primary system depends on both ground acceleration amplification in the primary structure and further amplification in the secondary system due to its own flexibility. As mentioned previously, ground acceleration amplification in the primary structure to the support location in ASCE 7-10 is equal to $(1+2 z / h)$, which reaches a maximum value of 3.0 if the secondary system is supported at the top of the primary

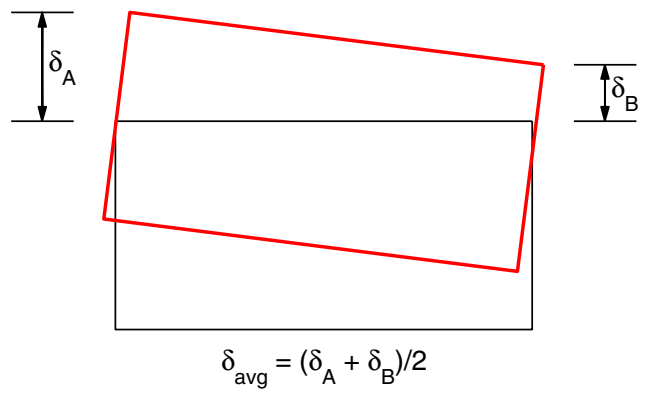

Figure 1. Displacements used in computation of torsional amplification factor, $A_{x}$ (adapted from ASCE 2010).

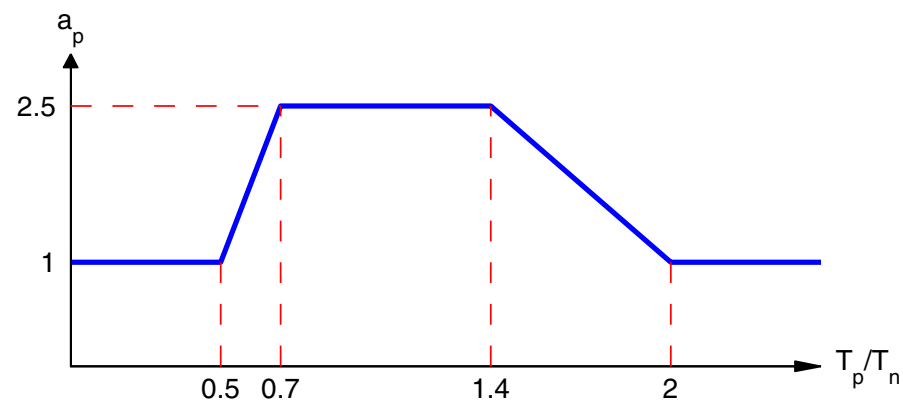

Figure 2. Value of $a_{p}$ as a function of component and structural period ratio (adapted from ASCE 2010). 
structure. The factor $a_{p}$ represents further acceleration amplification in the secondary system, which is equal to 1.0 for a rigid secondary system $\left(T_{p}<0.06 \mathrm{~s}\right)$ or 2.5 for a flexible secondary system.

Seismic response of nonstructural components has been a subject of interest for several decades now (e.g., Singh 1975 and 1988, Kelly and Sackman 1978 and 1979, Sackman and Kelly 1979 and 1980, Der Kiureghian et al. 1983, Gupta and Tembulkar, 1984, Igusa and Der Kiureghian 1985, Singh and Suarez 1986, Suarez and Singh 1987a, 1987b, and 1987c, Chen and Soong 1988, Gupta 1997). The scope of this early research includes understanding the seismic behavior of nonstructural components and their interaction with the primary structure in nuclear power structures, or developing methods to generate floor spectra that provide input for the design of nonstructural components. Later work (e.g., Soong et al. 1993, Miranda and Taghavi 2005a and 2005b, Drake and Bachman 1996, Singh et al. 2006a and 2006b, Taghavi and Miranda 2008, Fathali and Lizundia 2011) specifically focused on nonstructural components in building applications and eventually led to development of nonstructural component seismic provisions in FEMA-356, FEMA-450, and ASCE 7-10. But much of this work is applicable to buildings with multiple floors, which are multi-degree-of-freedom (MDOF) systems (e.g., Drake and Bachman 1996). However, many marine structures, such as piers, wharves, and marine oil terminals, consist of a single-level structure with a heavy deck supported on piles. Such structures are in many cases essentially single-degree-of-freedom (SDOF) systems. This simplification provides an opportunity to re-examine ground acceleration amplification in the primary structure instead of using $(1+2 z / h)$ in the ASCE 7-10 provision, which becomes equal to 3.0 for all secondary systems supported on the decks of piers, wharves, and marine oil terminals.

Chopra (2017) compared spectra for pseudo-acceleration (or spectral acceleration), $A$, and total (or true) acceleration, $\ddot{u}_{o}^{t}$, and concluded that $\ddot{u}_{o}^{t}$ is approximately equal to $A$ for low system-damping values. This observation suggests that spectral acceleration, $A$, at the fundamental vibration period of the primary system is a reasonable estimate of acceleration at the point of attachment of the secondary system, $a_{i}$, in Equation 2. However, Chopra's (2017) results are for a single ground motion only. It would be useful to examine this approximation for suite(s) of ground motions to develop confidence in its use for wider practical application.

Practicing engineers quite often have information on vibration periods of both primary structures (piers, wharves, and marine oil terminals) and secondary systems (ancillary components and nonbuilding structures). For such situations, the commentary in ASCE 7-10 provides guidelines for selecting the amplification factor, $a_{p}$, based on the ratio of the period of the secondary system, $T_{p}$, and the fundamental period of the primary system, $T_{n}$, (e.g., Figure 2). This guideline draws from the recommendation by Soong et al. (1993). However, because the background for this recommendation is not readily available, it is useful to re-examine this formulation.

The study described here (1) explores a simplified method to estimate acceleration at the point of attachment of the component, $a_{i}$; (2) investigates acceleration amplification due to secondary system flexibility; and (3) presents a simple procedure to estimate seismic forces in secondary systems supported on piers, wharves, and marine oil terminals. For this purpose, 
the study uses a simple linear-elastic model with two degrees of freedom, one representing the marine structure and the other representing the ancillary component.

The appropriateness of the upper- and lower-bound limits in Equation 1 are not investigated because such limits are often based on judgment and other factors that may not be readily captured in an analytical investigation. The simple procedure in this paper is strictly applicable when both the ancillary component and the supporting pier, wharf, or marine oil terminal can be individually idealized as an SDOF system. The effects of nonlinearity either in the primary system or the secondary system are not included; however, another study by the author (Goel 2017b) showed that forces in linear-elastic systems are generally larger and hence more conservative than those in corresponding nonlinear systems.

\section{GROUND MOTIONS}

To develop wider confidence in the applicability of its findings, the current investigation uses two suites of ground motions. The SAC suite, consisting of 20 ground motions, was developed by the SAC study for $10 \%$ probability of exceedance in 50 years for a site in Los Angeles, California (Somerville et al. 1997). The NGA-West2 suite, consisting of 80 ground motions from the NGA-West2 database (PEER 2013), is compatible with the Level-2 (or 10\% probability of exceedance in 50 years) MOTEMS site-specific spectrum for the Port of Long Beach, California. Figure 3 shows the elastic response spectrum for individual ground motions and the median for each suite. It is useful to clarify that both the primary and secondary systems in "actual" piers, wharves, and marine oil terminals may experience nonlinearity during selected ground motions and that linear behavior may only occur at a much lower level of ground shaking. However, these ground motions are still useful for understanding trends in the response quantities of interest - acceleration at the base of the secondary system and acceleration amplification in the secondary system due to its flexibility.

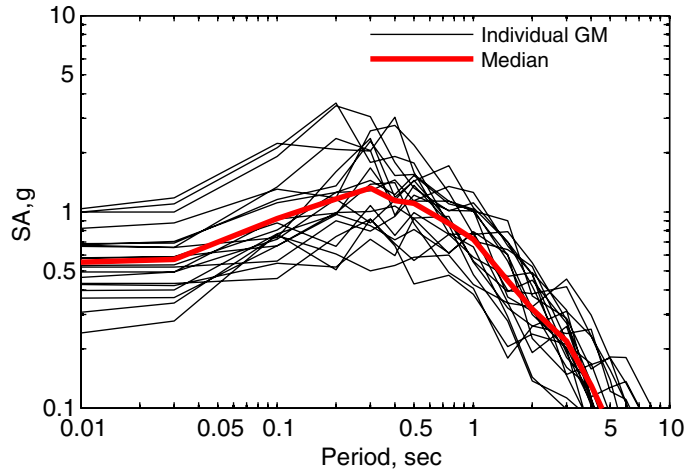

(a)

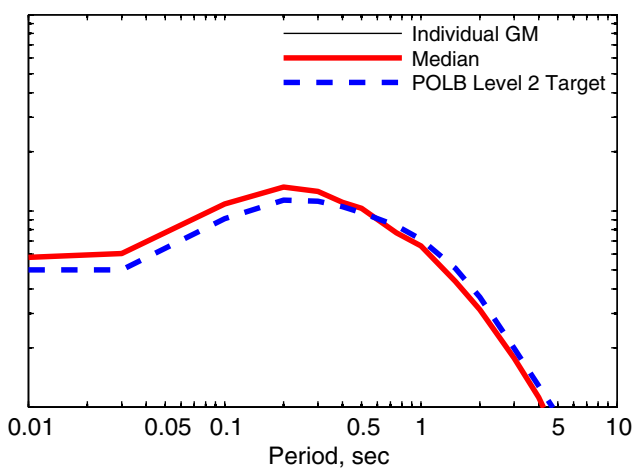

(b)

Figure 3. Response spectrum for (a) SAC ground motions and (b) NGA-West2 ground motions. 


\section{COMPARISON OF TRUE AND SPECTRAL ACCELERATIONS}

This investigation computes the peak value of total acceleration, $\ddot{u}_{o}^{t}$, and spectral acceleration, $A$, of SDOF systems for each ground motion in the SAC and NGA-West 2 suites. The damping ratio is set at $5 \%$, which is representative of the value used for spectral acceleration in ASCE 7-10 as well as in general engineering practice for seismic design of piers, wharves, and marine oil terminals. Figure 4 shows the ratio of $\ddot{u}_{o}^{t}$ and $A$ for each ground motion, and the median and 84th percentile for each suite. These results indicate that the ratio for each ground motion as well as the median and the 84th-percentile results for all earthquakes in a selected suite of ground motions are very close to one another over a wide range of period values. This observation is applicable for both ground motion suites and provides confidence that the conclusions here are widely applicable.

The results shown in Figure 4 for two suites of ground motions confirm the observation by Chopra (2017) that the true acceleration, $\ddot{u}_{o}^{t}$, for SDOF systems with low damping is approximately equal to the spectral acceleration, $A$. The values of $\ddot{u}_{o}^{t}$ and $A$ are theoretically identical for zero damping (Chopra 2017). Since the difference between $\ddot{u}_{o}^{t}$ and $A$ results only from damping forces, it increases with increasing damping, especially for longer-period systems for which damping plays an increasingly prominent role in seismic response.

It is useful to reiterate that many piers, wharves, and marine oil terminals are SDOF systems and that the seismic design of such structures uses a low damping value (5\%). Furthermore, the primary system supports the secondary system (ancillary components and nonbuilding structures) at its deck level, implying that acceleration at the base of the secondary system equals the total acceleration of the SDOF primary system. Therefore, it is recommended that Equation 2 use the spectral acceleration, $A$, selected from the seismic design spectra at the period equal to the fundamental vibration period of the primary system (pier, wharf, or marine oil terminal) in the direction under consideration for the acceleration, $a_{i}$, at the point of attachment of the secondary system.

Figure 4 examines the acceleration at the point of attachment of the secondary system to the primary system using a model that does not include the secondary system - that is,

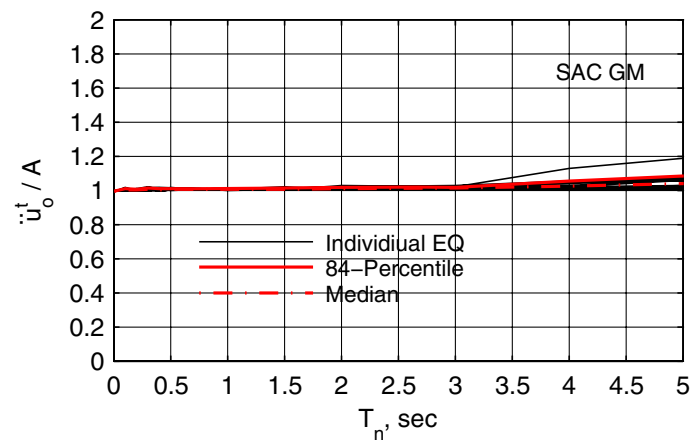

(a)

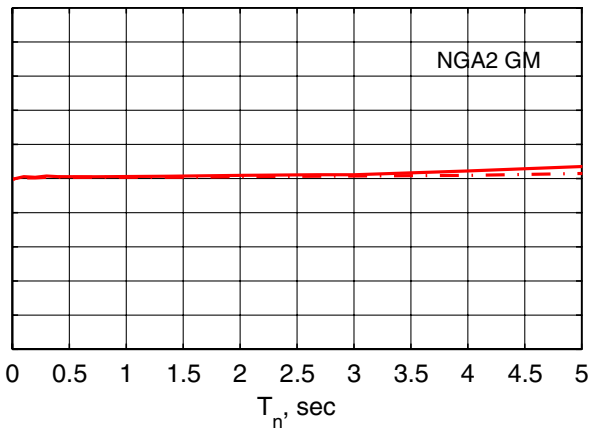

(b)

Figure 4. Ratio of $\ddot{u}_{o}^{t}$ and $A$ for (a) SAC ground motions and (b) NGA-West2 ground motions. 
an uncoupled model. The author used a coupled primary-secondary system model in another study (Goel 2017a) to examine this acceleration and found that the observations from Figure 4 remain generally valid except when the periods of the primary and secondary systems are close for a heavier secondary system, in which case the acceleration from the coupled system is slightly lower than that from the uncoupled system (Figure 4).

\section{ACCELERATION AMPLIFICATION DUE TO COMPONENT FLEXIBILITY}

This study uses a linear-elastic, coupled primary-secondary system model (Figure 5) to study acceleration amplification due to component flexibility. It defines amplification as the ratio of total accelerations at the top and base of the secondary system. The time variation in the accelerations shown in Figure 5 are for illustration only and do not represent actual accelerations that might occur in various cases.

The parameters that characterize the earthquake response of linear-elastic, coupled primary-secondary systems are (Goel 2017a): (1) the ratio of the mass of the secondary and primary systems, $\mu=m_{2} / m_{1} ;(2)$ the ratio of the vibration periods, $T_{p} / T_{n}$, where $T_{p}=$ $2 \pi \sqrt{m_{2} / k_{2}}$ is the vibration period of the secondary system alone and $T_{n}=2 \pi \sqrt{m_{1} / k_{1}}$ is the vibration period of the primary system alone; and (3) the damping ratio in two modes of vibration of the system.

This study computes the linear-elastic response history of the coupled primary-secondary system using OpenSees (McKenna and Fenves 2011). For damping, it uses a Rayleigh damping model with $5 \%$ damping in each of the two modes of the coupled system. Response history analysis results lead to the peak value of $\ddot{u}_{1, o}^{t}$, which is the total acceleration at the top of the primary system and the base of the secondary system, and to the peak value of $\ddot{u}_{2, o}^{t}$, which is the total acceleration at the top of the secondary system. The peak values of these two responses may not occur at the same time.
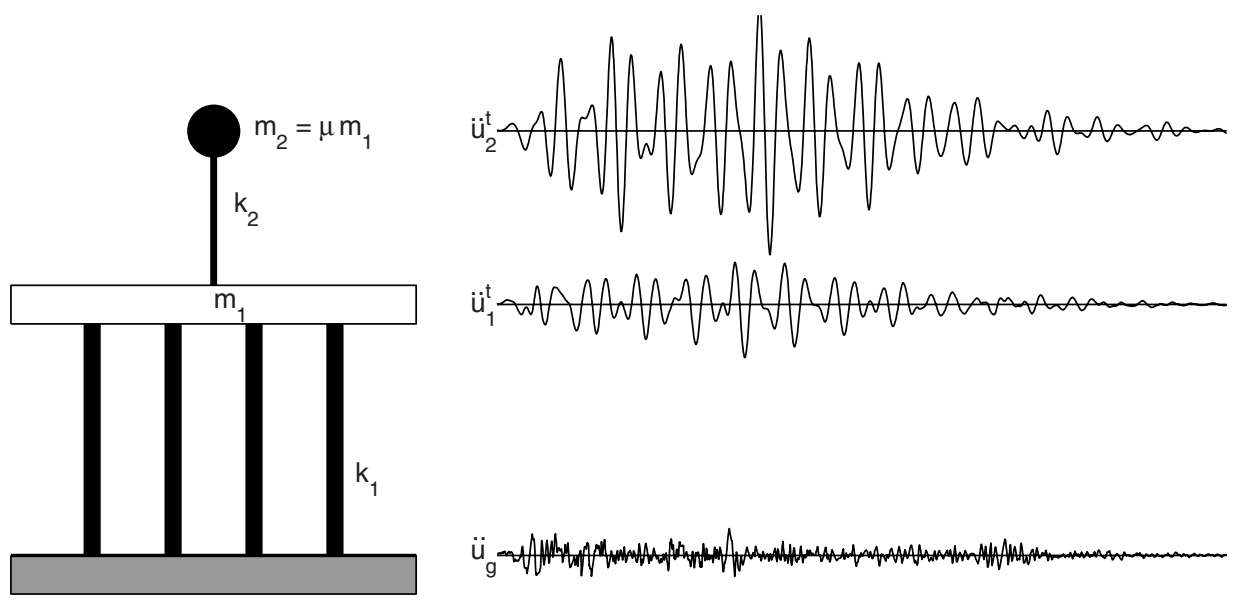

Figure 5. Coupled primary-secondary system model. 
The amplification of the acceleration due to flexibility in the secondary system is computed as the ratio of $\ddot{u}_{2, o}^{t}$ and $\ddot{u}_{1, o}^{t}$ for a range of $T_{n}$ values; six mass ratio values, $\mu=0.01$, $0.05,0.1,0.15,0.2$, and 0.25 ; and each individual ground motion as well as median and 84th-percentile values for the entire ground motion suite. The comprehensive set of results, available in Goel (2017a), indicates that $a_{p}$ is essentially independent of $T_{n}$. Therefore, this paper presents results for only one value of $T_{n}=1 \mathrm{~s}$.

Figures 6 and 7 present the amplification factors, $a_{p}=\ddot{u}_{2, o}^{t} / \ddot{u}_{1, o}^{t}$, for the SAC and NGAWest2 suites, respectively. For comparison, these figures also include ASCE 7-10 recommendations for flexible secondary systems and a variation of $a_{p}$ with $T_{p} / T_{n}$ in the ASCE 7-10 commentary (ASCE 2010). While the figures include the variation in $a_{p}$ with $T_{p} / T_{n}$ for each individual ground motion, only the trends primarily from the median and 84th-percentile curves are examined here.

The results in Figures 6 and 7 indicate that $a_{p}$ approaches 1.0 as $T_{p} / T_{n}$ approaches zero. This limiting value is expected because $T_{p} / T_{n}$ approaching zero implies a rigid secondary system for which no acceleration amplification should occur. This observation confirms the specification in ASCE 7-10 that $a_{p}=1$ for rigid secondary systems supported on primary systems. For values of $T_{p} / T_{n}>2$, the value of $a_{p}$ falls below 1.0. This implies acceleration de-amplification for very-flexible secondary systems. In other words, acceleration at the top of the secondary system is less than that at the base for systems with $T_{p} / T_{n}>2$. For systems with $0<T_{p} / T_{n} \leq 2, a_{p}$ is greater than 1.0 , indicating that acceleration of the secondary system is larger than that at its base. The maximum value of $a_{p}$ occurs when $T_{p} / T_{n}$ is close to 1 . For such a period ratio, the secondary system behaves as a tuned mass damper for the primary
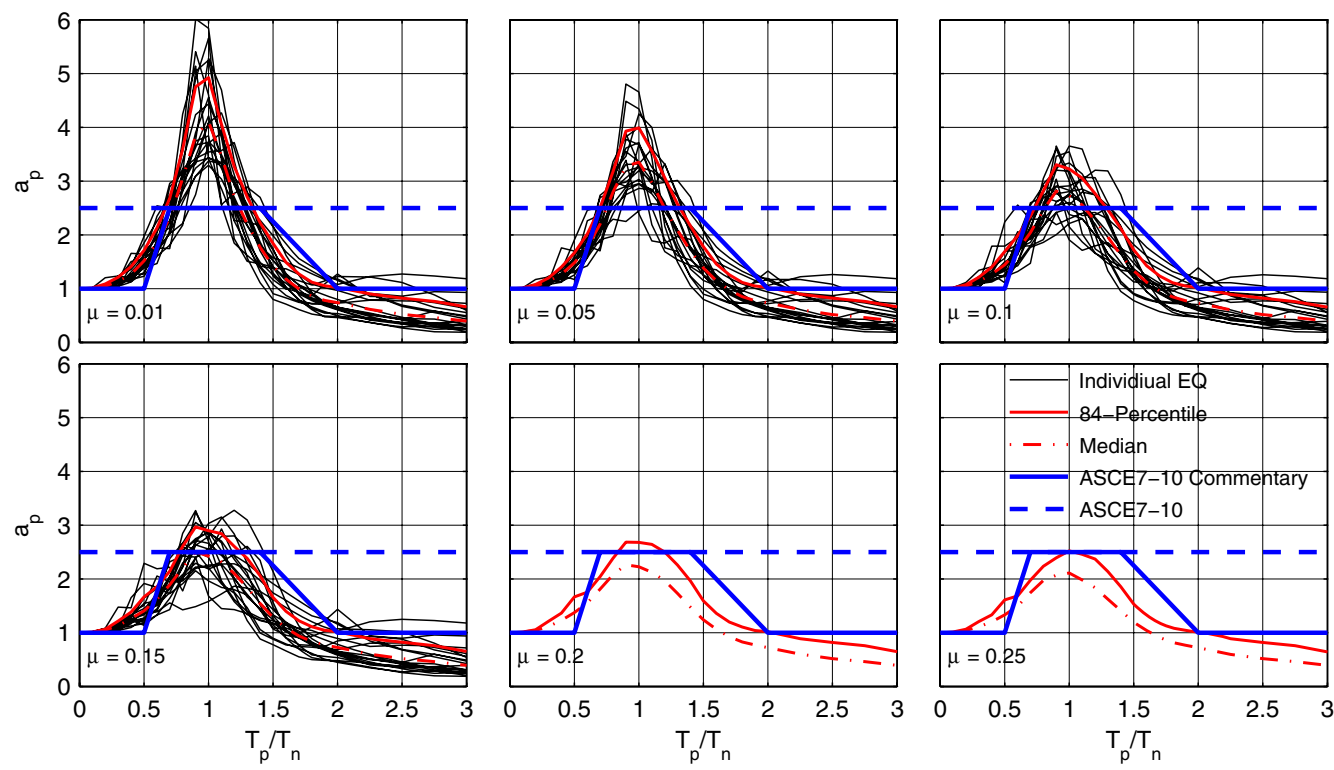

Figure 6. Amplification factor, $a_{p}$, for SAC suite of ground motions. 

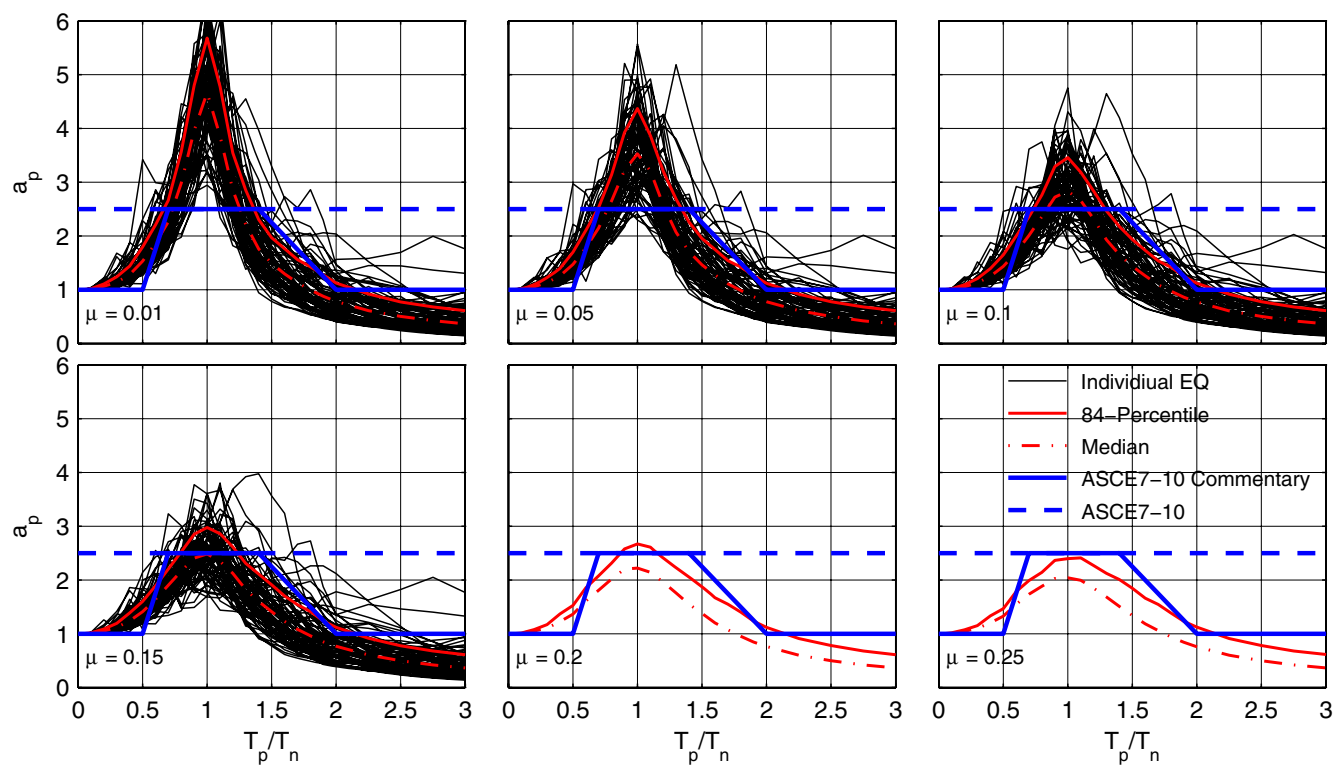

Figure 7. Amplification factor, $a_{p}$, for NGA-West2 suite of ground motions.

system and thus experiences large motions (Chopra 2017, sec. 12.2). The magnitude of amplification depends on value of $\mu$, which represents the ratio of the mass of the secondary system to that of the primary system. The peak of $a_{p}$ tends to be much higher for systems with low values of $\mu$ compared to systems with high values. This implies that a more careful assessment of lighter secondary systems is needed, especially if $T_{p} / T_{n}$ falls in the range where $a_{p}$ peaks. These trends are consistent for both SAC and NGA-West2 ground motions suites.

As mentioned previously, ASCE 7-10 specifies $a_{p}=2.5$ for flexible secondary systems (i.e., $T_{p}>0.06 \mathrm{~s}$ ). Clearly, this amplification is larger than that observed in this study for many cases, especially for systems with $T_{p} / T_{n}<0.6$ and $T_{p} / T_{n}>1.4$. This provision appears to be adequate for systems with $0.6<T_{p} / T_{n}<1.4$ only when $\mu \geq 0.02$ - that is, when the secondary system weighs $20 \%$ or more than the primary system. For systems with $0.6<T_{p} / T_{n}<1.4$ and $\mu<0.2$ - that is, lighter secondary systems-amplification tends to be excessive and $a_{p}=2.5$ is not sufficient to capture it.

The $a_{p}$ recommendation in the ASCE 7-10 commentary appears to be adequate when $T_{p} / T_{n}>1.4$ for all $\mu$ values. It is also adequate when $0.6<T_{p} / T_{n}<1.4$ and $\mu \geq 0.2$. However, amplification is excessive and often exceeds the ASCE 7-10 recommendation when $0.6<T_{p} / T_{n}<1.4$ and $\mu<0.2$, implying that such a recommendation leads to lower than expected forces in lighter secondary systems. Finally, the ASCE 7-10 recommendation may also lead to slightly lower than expected forces for secondary systems with $T_{p} / T_{n}<0.6$ irrespective of the $\mu$ value, as is apparent from the observation that both the median and the 84th-percentle curves are higher than the recommendation. 
Figures 6 and 7 include median and 84th-percentile curves for the SAC and NGAWest 2 ground motion suites. As expected, the median curves tend to be slightly lower than the corresponding 84th-percentile curve. However, the overall observations in the preceding paragraphs are similar for both sets of results.

\section{RECOMMENDATION FOR AMPLIFICATION FACTOR}

The preceding section identified several shortcomings of the ASCE 7-10 recommendation for the amplification factor, $a_{p}$. In particular, for flexible secondary systems it may lead to larger than expected forces in systems with $T_{p} / T_{n}<0.6$ and $T_{p} / T_{n}>1.4$, and to significantly lower than expected forces in lighter secondary systems, where $\mu<0.2$, when $0.6<T_{p} / T_{n}<1.4$. While the recommendation provides a better value for $a_{p}$ in some cases, it is inadequate in many other. For example, it tends to provide slightly lower than expected forces in systems with $T_{p} / T_{n}<0.6$ and significantly lower than expected forces in lighter secondary systems, (i.e., $\mu<0.2$ ) when $0.6<T_{p} / T_{n}<1.4$.

Based on the observations so far, this paper proposes a revised relationship between $a_{p}$ and $T_{p} / T_{n}$ as follows:

$$
a_{p}=\left\{\begin{array}{llll}
1.0 & & & T_{p} / T_{n} \leq 0.1 \\
1.0+3 & T_{p} / T_{n} \quad 0.1 & 0.1<T_{p} / T_{n}<0.6 \\
2.5(\text { not applicable for } \mu<0.2) & 0.6 \leq T_{p} / T_{n} \leq 1.4 \\
2.5 & 2.5 & T_{p} / T_{n} \quad 1.4 & 1.4<T_{p} / T_{n}<2.0 \\
1.0 & & &
\end{array}\right.
$$

Equation 4 is not applicable for lighter secondary systems $(\mu<0.2)$ with period ratios in the range of $0.6<T_{p} / T_{n}<1.4$. For such configurations, the secondary system behaves as a tuned mass damper and thus experiences large accelerations that may not be readily accommodated in its seismic design.

Figures 8 and 9 compare the results using the amplification in Equation 4 against median and 84th-percentile results, respectively. It is shown that the revised recommendation of Equation 4 provides much better estimates of $a_{p}$ compared to ASCE 7-10. Equation 4 also encompasses both the median and 84th-percentile results. As expected, the 84thpercentile values of $a_{p}$ (Figure 9) are higher than the median values (Figure 8). However, the differences are small, so it may be concluded that Equation 4 provides a reasonably good estimate of $a_{p}$.

\section{RECOMMENDED FORMULA FOR FORCE IN ANCILLARY COMPONENTS}

Based on the findings so far, the following simple procedure is proposed to estimate seismic forces in ancillary components and nonbuilding structures supported on piers, wharves, and marine oil terminals:

$$
F_{p}=\frac{a_{p} A I_{p} A_{x} W_{p}}{R_{p}}
$$



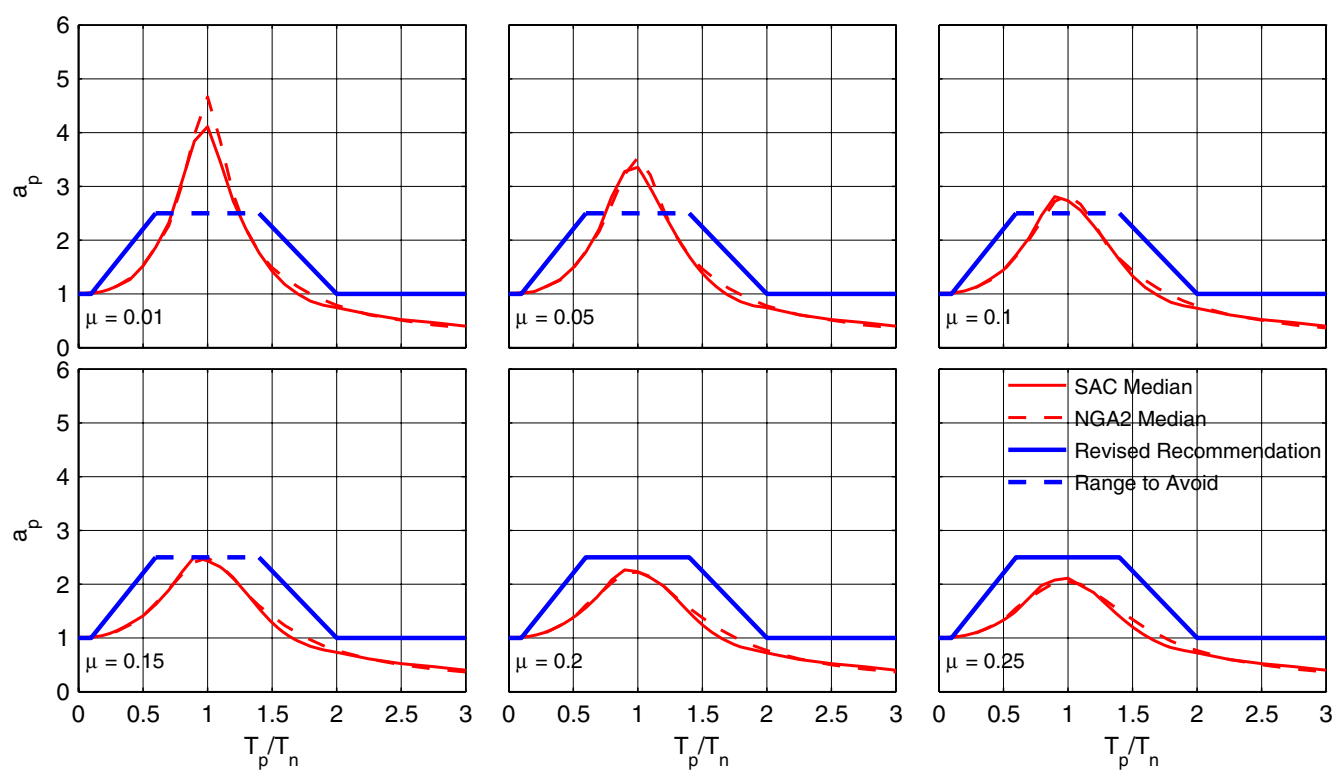

Figure 8. Recommended amplification factor, $a_{p}$, and median values for SAC and NGA-West2 ground motion suites.
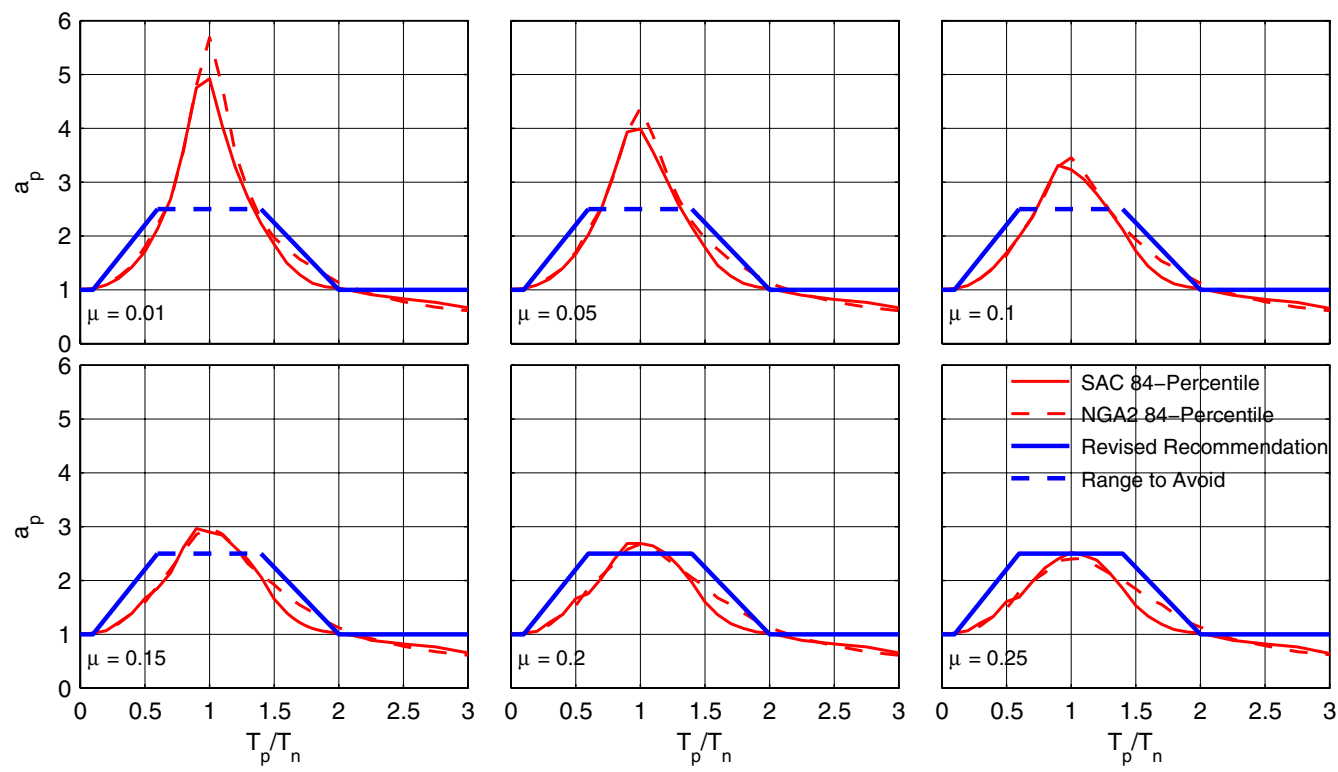

Figure 9. Recommended amplification factor, $a_{p}$, and 84th-percentile values for SAC and NGA-West2 ground motions suites. 
in which $A$ is the spectral acceleration computed from the design earthquake spectrum at a period equal to the fundamental vibration period of the primary system - that is, the pier, wharf, or marine oil terminal; $a_{p}$ is the acceleration amplification factor due to the flexibility of the secondary system - that is, the ancillary component or nonbuilding structure, given by Equation 4.

Equation 5 modifies two important aspects of the current ASCE 7-10 recommendation: it replaces either $0.4 S_{D S}(1+2 z / h)$ in Equation 1 or $a_{i}$ in Equation 3 with $A$, and uses a slightly modified formula for $a_{p}$ in Equation 4. It also prohibits using this procedure for lighter secondary systems $(\mu<0.2)$ designed in the period ratio range $0.6<T_{p} / T_{n}<1.4$ because such configurations exhibit excessive acceleration amplification.

The combined effects of both modifications on the acceleration (and force) in the ancillary systems are examined in Figure 10-12. These figures compare the 84th-percentile values of $\ddot{u}_{2 o} / \ddot{u}_{g o}$ for the SAC suite of ground motions with the results from ASCE 7-10 recommendations and the procedure proposed in this paper. The results for median trends and for the NGA-West2 ground motion suite are omitted for brevity but are available in Goel (2017a).

The results show that the procedure proposed in this paper provides excellent estimates of acceleration in the ancillary system over the entire period range of the primary system and of the mass ratio in the secondary and primary systems when the period ratio in those systems is either very low or very high: $T_{p} / T_{n}=0.1$ or 2 (Figures 10 and 12). For the same range of
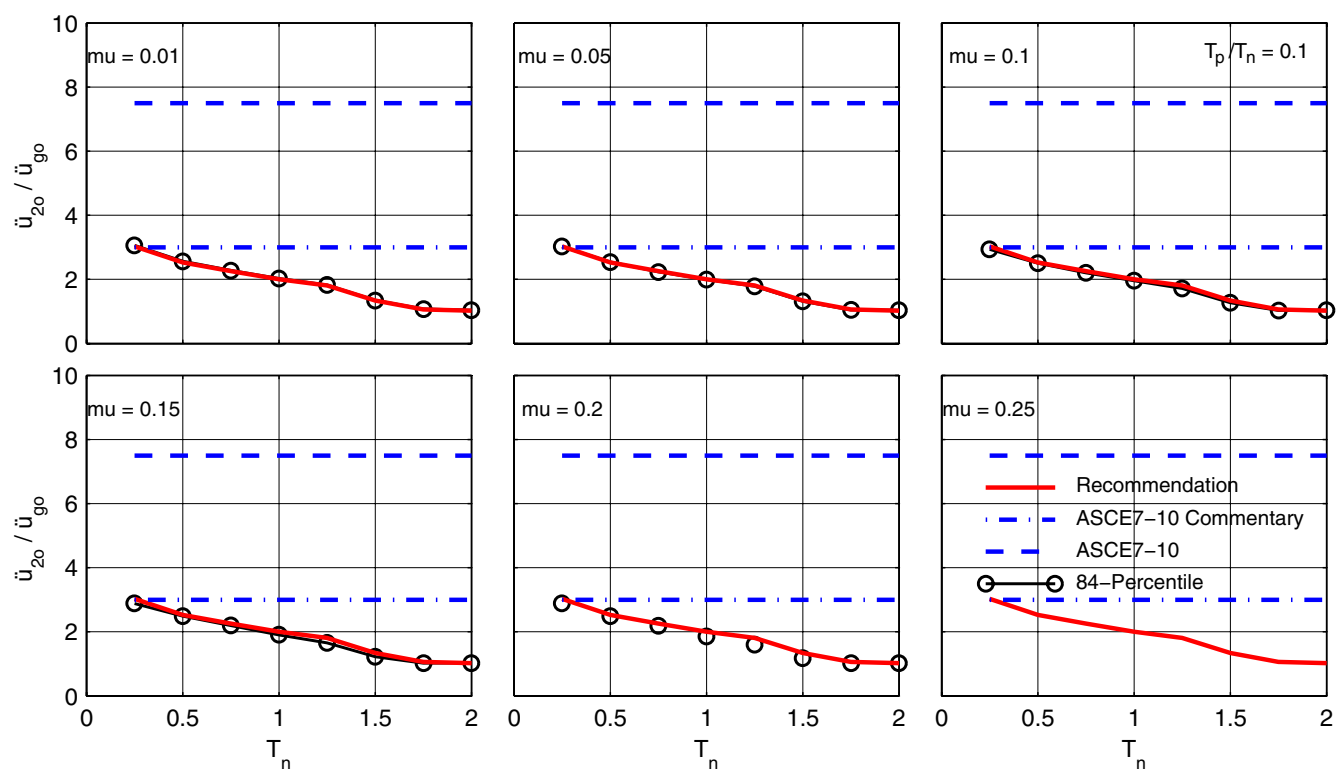

Figure 10. Comparison of combined effects of acceleration amplification from the ground to the point of attachment of the secondary system and secondary system flexibility. Results are for 84th-percentile values, SAC ground motions, various mass ratios, $\mu$, and $T_{p} / T_{n}=0.1$. 

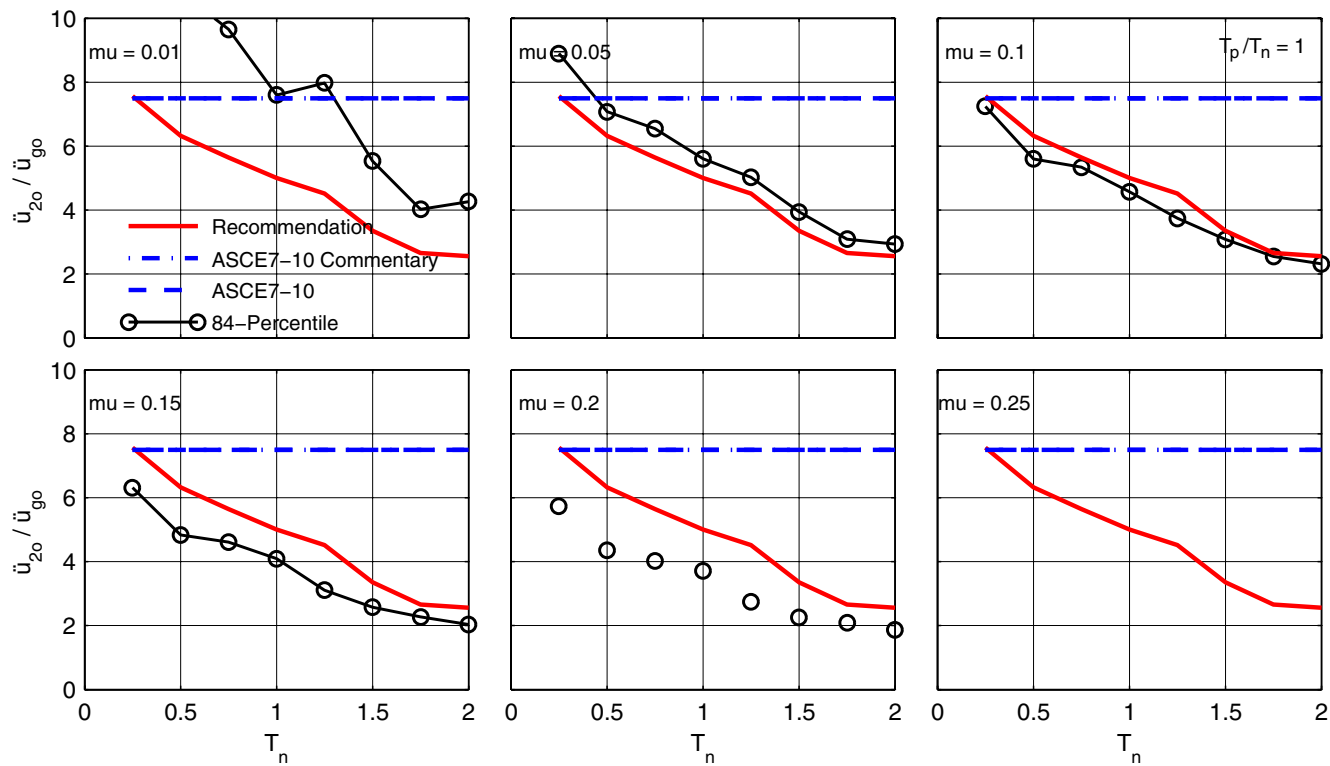

Figure 11. Comparison of combined effects of acceleration amplification from the ground to the point of attachment of the secondary system and secondary system flexibility. Results are for 84th-percentile values, SAC ground motions, various mass ratios, $\mu$, and $T_{p} / T_{n}=1$.
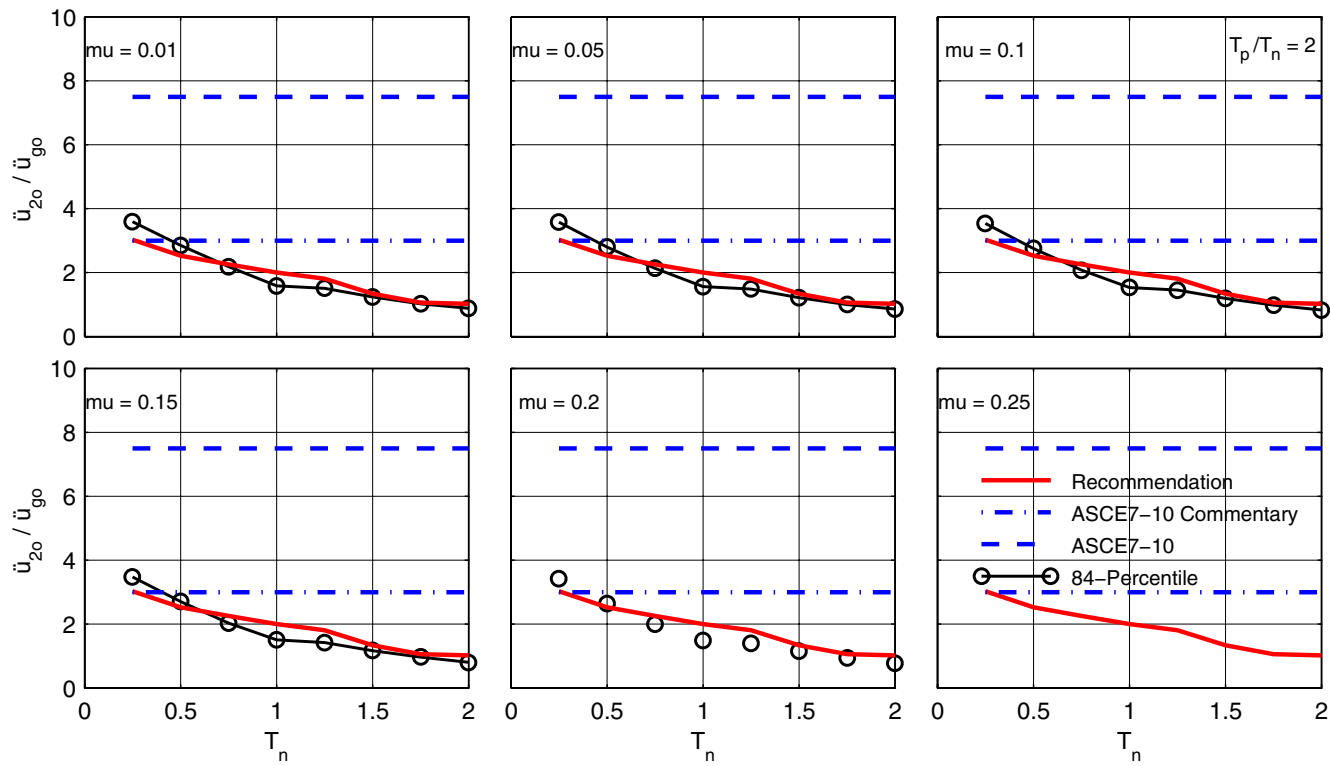

Figure 12. Comparison of combined effects of acceleration amplification from the ground to the point of attachment of the secondary system and secondary system flexibility. Results are for 84th-percentile values, SAC ground motions, various mass ratios, $\mu$, and $T_{p} / T_{n}=2$. 
system parameters, the ASCE 7-10 recommendation produces significantly larger accelerations compared to observed values. It provides very good estimates for very-short-period primary systems but larger than observed accelerations for longer-period primary systems; this difference increases with as the period increases.

For systems where secondary- and primary-system vibration periods are close, the procedure proposed in this paper provides estimate slightly larger than observed values when the mass ratio, $\mu$, is greater than 0.05 ; the difference widens as the mass ratio continues to increase (Figure 11). This trend reverses for systems with mass ratio, $\mu$, equal to or less than less than 0.05 , however. The ASCE 7-10 recommendations generally provide accelerations that are much larger than observed values. It is useful to note that they provide the same results for $T_{p} / T_{n}=1$ (Figure 11).

Figure 11 also confirms the original caveat that the proposed procedure not be used for lighter secondary systems designed in the period ratio range $0.6<T_{p} / T_{n}<1.4$ because such systems exhibit excessive acceleration amplifications.

Figures 10-12 present results for limited values of $T_{p} / T_{n}$ for 84 th-percentile results and the SAC suite of ground motions only. Additional results available in Goel (2017a) show that the trends in Figure 10-12 hold for other cases as well.

\section{CONCLUSIONS}

This paper discussed a study of seismic forces in ancillary components and nonbuilding structures supported on piers, wharves, and marine oil terminals. Currently the only provisions available for such systems are found in ASCE 7-10. However, this standard applies primarily to seismic analysis and design of buildings. We can idealize many piers, wharves, and marine oil terminals, which are essentially one-level structures, as SDOF systems. For this reason, this study focused on the seismic response of a simple linear-elastic model with two degrees of freedom - one representing the marine structure and the other representing the ancillary component - to develop a simple procedure to compute seismic forces in the secondary system supported on piers, wharves, and marine oil terminals. The results lead to the following conclusions:

- We can approximate acceleration, $a_{i}$, at the base of the secondary system by the spectral acceleration value, $A$, at a period equal to the fundamental period, $T_{n}$, of the primary structure (i.e., pier, wharf, or marine oil terminal) in the direction under consideration.

- The ASCE 7-10 amplification factor, $a_{p}$, for flexible secondary systems tends to be higher for systems with $T_{p} / T_{n}<0.6$ or $T_{p} / T_{n}>1.4$ and significantly lower for systems with $0.6<T_{p} / T_{n}<1.4$ and mass ratio $\mu<0.2$ compared to the values observed in this study.

- The ASCE 7-10 recommendation provides a better estimate of $a_{p}$ but tends to be slightly lower for systems with $T_{p} / T_{n}<0.6$ and significantly lower for systems with $0.6<T_{p} / T_{n}<1.4$ and mass ratio $\mu<0.2$ compared to observed values.

A simplified procedure to estimate seismic forces in ancillary components and nonbuilding structures supported on piers, wharves, and marine oil terminals is proposed. This procedure leads to much improved estimates of acceleration, and thus force, 
in ancillary systems for a wide range of parameters when compared to current ASCE 7-10 recommendations.

This study utilizes coupled primary-secondary systems, where both the secondary ancillary component and the primary structure (i.e., pier, wharf, or marine oil terminal) can individually be idealized as a linear-elastic SDOF system. Therefore, the recommendations and conclusions in this paper are strictly applicable only to such systems.

\section{ACKNOWLEDGMENTS}

The early part of this research was supported by the California State Lands Commission (CSLC) under Contract No. C2013-054. This support is gratefully acknowledged.

\section{REFERENCES}

ASCE (American Society of Civil Engineers), 2014. Seismic Design of Piers and Wharves, ASCE/COPRI 61-14, Reston, VA.

ASCE (American Society of Civil Engineers), 2011. Guidelines for Seismic Evaluation and Design of Petrochemical Facilities, 2nd ed., New York.

ASCE (American Society of Civil Engineers), 2010. Minimum Design Loads for Buildings and Other Structures, ASCE/SEI 7-10, Reston, VA.

American Society of Civil Engineers (ASCE), 2000. Prestandard and Commentary for the Seismic Rehabilitation of Buildings, Report No. FEMA 356, Federal Emergency Management Agency, Washington, D.C.

BSSC (Building Seismic Safety Council), 2003. NEHRP Recommended Provisions for Seismic Regulations for New Buildings and Other Structures, Parts 1 and 2, Report FEMA 450, Federal Emergency Management Agency, Washington, D.C.

CalARP Program Seismic Guidance Committee, 2013. Guidance for California Accidental Release Prevention (CalARP) Program Seismic Assessment, Administrative Agency Subcommittee, Region I Local Emergency Planning Committee (LEPC), Sacramento, CA.

CSLC (California State Lands Commission), 2016. Marine Oil Terminal Engineering and Maintenance Standards (MOTEMS), Title 24, California Code of Regulations, Part 2, Sacramento.

Chen, Y., and Soong, T. T., 1988. Seismic response of secondary systems, Engineering Structures 10(4), 218-228.

Chopra, A. K., 2017. Dynamics of Structures: Theory and Applications to Earthquake Engineering, 5th ed., Pearson, Hoboken, NJ.

DoD (Department of Defense), 2017. Design: Piers and Wharves, UFC 4-152-01, Washington, D.C.

Der Kiureghian, A., Sackman, J. L., and Nour-Omid, B., 1983. Dynamic analysis of light equipment in structures: response to stochastic input, Journal of Engineering Mechanics 109(1), 90-110.

Drake, R. M., and Bachman, R. E., 1996. NEHRP provisions for 1994 for nonstructural components, Journal of Architectural Engineering 2(1), 26-31.

Fathali, S., and Lizundia, B., 2011. Evaluation of current seismic design equations for nonstructural components in tall buildings using strong motion records, Structural Design of Tall Buildings 20, S30-S46. 
Goel, R. K., 2017a. Seismic Response of Coupled Primary-Secondary Systems in Piers, Wharves, and Marine Oil Terminals, Report No. CP/SEAM-2017/01, California Polytechnic State University, San Luis Obispo, CA, https://works.bepress.com/rgoel/64/.

Goel, R. K., 2017b. Effects of Nonlinearity in Primary System on Accelerations in Secondary Systems: Piers, Wharves, and Marine Oil Terminals, Report No. CP/SEAM-2017/02, California Polytechnic State University, San Luis Obispo, CA, https://works.bepress.com/rgoel/65/.

GPO (Government Printing Office), 2017. Code of Federal Regulations, Title 33 Section 154.510 (33CFR 154.510), Washington, D.C., https://www.ecfr.gov.

Gupta, A. K., and Tembulkar, J. M., 1984. Dynamic decoupling of secondary systems, Nuclear Engineering and Design 81(3), 359-373.

Gupta, V. K., 1997. Acceleration transfer function of secondary systems, Journal of Engineering Mechanics 123(7), 678-685.

Igusa, T., and Der Kiureghian, A., 1985. Generation of floor response spectra including oscillator-structure interaction, Earthquake Engineering \& Structural Dynamics 13(5), 661-676.

Kelly, J. M., and Sackman, J. L., 1979. Shock Spectra Design Method for Equipment in Impulsively Loaded Structures, Report prepared for the Defense Nuclear Agency, Weidlinger Associates, Menlo Park, CA.

Kelly, J. M., and Sackman, J. L., 1978. Response spectra design methods for tuned equipmentstructure systems, Journal of Sound and Vibration 59(2), 171-179.

McKenna, F., and Fenves, G., 2011. OpenSees, Version 2.3.1, Pacific Earthquake Engineering Center, University of California, Berkeley, CA, http://www.opensess.berkeley.edu.

Miranda, E., and Taghavi, S., 2005a. Approximate floor acceleration demands in multistory buildings. I: Formulation, Journal of Structural Engineering 131(2), 203-211.

Miranda, E., and Taghavi, S., 2005b. Approximate floor acceleration demands in multistory buildings. II: Applications, Journal of Structural Engineering 131(2), 212-220.

OAL (Office of Administrative Law), 2017. California Code of Regulations, Title 2, Section 2380 (b), Loading Arms, Thomason-West/Barclays, San Francisco, CA, http://www.barclaysccr.com.

OCIMF (Oil Companies International Marine Forum), 1999. Design and Construction Specifications for Marine Loading Arms, 3rd ed., Witherby, London.

PEER (Pacific Earthquake Engineering Research Center), 2013. NGA-West2 Ground Motion Database, University of California, Berkeley, CA, http://ngawest2.berkeley.edu.

POLB (Port of Long Beach), 2012. Port of Long Beach Wharf Design Criteria, Version 3.0, Long Beach, CA.

POLA (Port of Los Angeles), 2010. Port of Los Angeles Code for Seismic Design, Upgrade and Repair of Container Wharves, City of Los Angeles Harbor Department, Los Angeles, CA.

POSF (Port of San Francisco), 2012. Seismic Engineering Standard-Piers, Wharves, and Seawall Structures, San Francisco, CA.

Sackman, J. L., and Kelly, J. M., 1980. Equipment Response Spectra for Nuclear Power Plant Systems, Nuclear Engineering and Design 57(2), 277-294.

Sackman, J. L., and Kelly, J. M., 1979. Seismic analysis of internal equipment and components in structures, Engineering Structures 1(4), 179-190.

Singh, M. P., 1988. Seismic design of secondary systems, Probabilistic Engineering Mechanics 3(3), 151-158.

Singh, M. P., 1975. Generation of seismic floor spectra, Journal of Engineering Mechanics 101(EM5), 593-607. 
Singh, M. P., Moreschi, L. M., Suarez, L. E., and Matheu, E. E., 2006a. Seismic design forces. I: Rigid nonstructural components, Journal of Structural Engineering 132(10), 1524-1532.

Singh, M. P., and Suarez, L. E., 1986. A perturbation analysis of the eigenproperties of equipment-structure systems, Nuclear Engineering and Design 97(2), 167-185.

Somerville, P., Smith, N., Punyamurthula, S., and Sun, J., 1997. Development of Ground Motion Time Histories for Phase 2 of the FEMA/SAC Steel Project, SAC Background Document Report No. SAC/BD-9/04, SAC Joint Venture, Sacramento.

Soong, T. T., Chen, C., Wu, Z., Zhang, R.-H., and Grigoriu, M., 1993. Assessment of the 1991 NEHRP Provisions for Nonstructural Components and Recommended Revisions, Report No. NCEER-93-0003, National Center for Earthquake Engineering Research, Buffalo, NY.

Suarez, L. E., and Singh, M. P., 1987a. Perturbed complex eigenproperties of classically damped primary structure and equipment systems, Journal of Sound and Vibration 116(2), 199-219.

Suarez, L. E., and Singh, M. P., 1987b. Floor response spectra with structure-equipment interaction effects by a mode synthesis approach, Earthquake Engineering \& Structural Dynamics 15(2), 141-158.

Suarez, L. E., and Singh, M. P., 1987c. Eigenproperties of nonclassically damped primary structure and oscillator systems, Journal of Applied Mechanics 54(3), 668-673.

Taghavi, S., and Miranda, E., 2008. Effect of interaction between primary and secondary systems on floor response spectra, Proceedings of the 14th World Conference on Earthquake Engineering, Beijing, 12-17.

(Received 10 April 2017; accepted 2 January 2018) 